\title{
Improving the teaching quality of new teachers by integrating multiple practical models of lesson study
}

\author{
Jingjing Zhao ${ }^{1, a, *}$, Xingtong Liu ${ }^{2, b}$ \\ ${ }^{1}$ College of Liberal Arts and Science, National University of Defense Technology, Changsha, Hunan, \\ China \\ ${ }^{2}$ College of Electronic Science, National University of Defense Technology, Changsha, Hunan, \\ China
}

ajjzhao1983@126.com, bliuxingtong@nudt.edu.cn

${ }^{*}$ Corresponding author

Keywords: Lesson study, New teachers, Teaching quality

\begin{abstract}
As an educational teacher mode to enhance teaching ability, lesson study has been accepted by more and more educators. Lesson study is based on lesson examples, emphasizing the promotion of teaching quality in dynamic research. To do well in teaching work, teachers need to have teaching design ability, professional research ability and critical reflection ability. The training of these abilities can be done with the aid of lesson study. Based on the perspective of training new teachers' teaching ability, this paper studies how to improve the teaching quality by using different practical models of lesson study in stages and conditions. Practice has shown that this is a long-term and efficient way.
\end{abstract}

\section{Introduction}

Lesson study is a kind of teacher education mode which takes lessons as the carrier and carries out the professional theoretical study and teaching ability in the teaching action [1]. Lesson study is a dynamic research process for a teaching problem and teaching decision [2]. Lesson study has made a good combination of theory and practice, what's more, it focuses on students' learning and attaches importance to teachers' cooperation. The spread and promotion of lesson study in the world also fully illustrates its effectiveness. However, at present, lesson study focuses on specific disciplines, specific research methods and specific practice models. On the one hand, it makes the lesson study more in-depth. However, on the other hand, it focuses on the problem rather than the long-term direction, so that the current lesson study is focused on the curriculum itself, not the long-term development of the new teachers. From the perspective of improving the new teachers' teaching ability, this paper studies how to make use of a variety of practical models of lesson study, and how to improve the teaching level of new teachers in stages to help them to adapt to the teaching work steadily.

\section{Teaching and related abilities that teachers need to possess}

On the one hand, the improvement of new teachers' teaching level is based on good professional knowledge background and presentation ability, on the other hand, it depends on teaching methods and teaching skills. At the beginning of the teaching career, the new teachers should make a good job of career planning, and then make clear the ability needed to carry out their teaching activities, so as to conduct targeted learning and training. Generally speaking, teachers need to have the following abilities in carrying out teaching activities.

\subsection{Teaching design ability}

Effective teaching design is an important way to improve teaching quality. Through the teaching design to build the classroom, so as to really make the students be centered in the teaching, kindle the interest of the students, and get the students to acquire knowledge in the process of exploration, which 
is the responsibility and mission of the teachers. There are many models of instructional design, such as the BOPPPS model [3]. It contains six teaching links, which are, bridge-in, outcome, pre-test, participation, post-test and summary. In practice, we need to consider following problems. For example, how do you choose an introduction? How to design teaching goals? How to adjust dynamically according to the pre-test situation? How to introduce participation? Each of these teaching links needs careful design. Therefore, teaching design ability is an important part of teachers' professional expertise. It is necessary for the new teachers to conduct extensive research before teaching and to integrate the different teaching materials on the basis of the actual needs and construct the teaching content. The new teachers gradually improve their teaching design ability by teaching design refined.

\subsection{Professional research ability}

Solid professional knowledge is the guarantee of improving teaching quality. Today, with the explosion of knowledge and the popularization of scientific rationality, the updating speed of knowledge is faster and faster. Therefore, teachers should keep the habit of lifelong learning, deepening their research on their professional fields, renewing their knowledge system, optimizing the structure of knowledge, and realizing the mutual promotion of teaching and learning. Only in this way, teachers can explain the difficult problems in simple language and thorough analysis.

\subsection{Critical reflection ability}

Critical reflection ability is an inexhaustible motive force for improving teaching quality. The improvement of teaching quality is a gradual process. Teachers need to find problems in time in the course of teaching and solve problems creatively through analytical reasoning and case study. Teachers who teach preaching need to keep an open and enterprising attitude, analyzing and reflecting on their own success and shortcomings in the teaching process from facts. In the course of teaching, teachers should constantly examine and evaluate themselves and treat the problems in teaching from the perspective of others, so as to face the problems in teaching, reflect on their own teaching design and teaching process, adjust the teaching methods and improve the content of teaching.

\section{New teachers' ability promotion scheme based on lesson study}

\subsection{Using network lessons and different teaching modes to get inspiration extensively}

An important problem that new teachers need to solve before formal class is how to design curriculum according to a given topic. In the Internet era today, we have a large number of online course resources. Therefore, before the opening of the class, the new teacher can listen to a wide range of courses related to the teaching content on the network to get the inspiration of teaching. At the same time, in real life, new teachers can walk into the classroom of old teachers to feel how different people teach according to their own characteristics. We can intuitively feel the diversity of curriculum through the way of visiting a class in the Internet and in reality. Due to different backgrounds, different teachers have different teaching personality and teaching styles. New teachers should be good at learning from others' experiences and practices in an open and pluralistic teaching environment to form their own teaching characteristics.

\subsection{Improving teaching design ability with one person and several rounds of lesson study model}

One-person multi-round lesson study model is widely used at present, especially in the pre-class trial activities of new teachers. Generally speaking, the first lesson is often prepared by the new teacher independently and try to show the new teacher's understanding and cognition of the subject. At the same time, it also exposes some problems in the teaching concept and teaching behavior of the young teachers. The teaching team can analyze the problems that exist in the teacher's independent lesson 
preparation, affirm the advantages, point out the shortage, and find the solution through the discussion, and form the second course design then. After the second lesson, the new teacher and the teaching team make a comparison of the contents of the previous two classes, analyze the progress, make clear the still existing problems, further revise the teaching plan and prepare the third classes. In this way, a cycle is formed, the new teachers reflect on this process and form their own teaching cases.

This method can help new teachers to solve the more obvious problems in teaching, clarify the teaching ideas and deepen the understanding of the curriculum. However, there is also a problem, that is, among the numerous opinions and suggestions, new teachers are prone to lose their own style and original ideas, and even feel confused. This requires new teachers to have a relatively independent time to reflect on the whole process. This is the unique effectiveness of the reflective class.

\subsection{Finding out teaching problems with reflective lesson study}

Nowadays, the rapid development of multimedia provides an effective guarantee for our reflective class. In this lesson study model, the new teacher becomes an observer in his or her own class. Through the repeated viewing of their own teaching videos, the new teachers can analyze and reflect on the success and lack of their own courses in a realistic way, and deeply understand their own teaching behavior and teaching effects. This model can help us to reflect on the problems in our teaching more objectively and comprehensively, especially the problems that are easily ignored, such as the use of teaching language and so on.

\subsection{Getting feedback from others through mutual aid lesson and invitation lesson}

After the new teachers start formal teaching, they can use mutual aid lesson and invitation lesson to learn the evaluation of colleagues and experts. Mutual aid lesson is usually horizontal assistance among colleagues. The invited lesson is the lesson that new teacher invite experts to visit his or her class. New teachers can get the experts' suggestion by this way. Mutual aid lesson focuses on teaching exchanges among colleagues, emphasizing the discovery and diagnosis problems. The invitation lesson is the guidance of teaching experts to teachers. It emphasizes evaluation and check. The effective combination of the two can enable new teachers to get more comprehensive and objective multi angle evaluation.

\subsection{Getting feedback from the students}

The ultimate goal of the lesson study is to improve the quality of teaching. The main body of teaching is the students. Therefore, new teachers must maintain timely communication with students and understand their feelings. Teachers need to dynamically adjust their teaching according to students' needs and feedback, so that students can fully grasp the teaching content. The questionnaire, with the classroom test, the interview students and so on are very good communication methods, which can help new teachers get first-hand information, thereby correcting and improving the teaching design, and ultimately upgrading the quality of teaching.

\section{Summary}

Every new teacher is faced with such problems: how to make the first lesson in his or her career? And how to improve the quality of teaching quickly? There are many answers to the questions, and there are many factors that affect the quality of teaching. Besides subjective responsibility and good learning attitude, new teachers also need to grasp reasonable methods. In the field of teaching, lesson study has made a number of achievements, which provides a good practical model for us to improve classroom teaching. Especially for new teachers, using the method of multiple lesson studies flexibly to explore teaching problems and construct classroom, can help to steadily improve the quality of teaching. 


\section{Acknowledgement}

This work was supported by Hunan Provincial NSF of China under Grant 2015JJ3018, and Preresearch project of National University of Defense Technology under Grant JS17-03-19.

\section{References}

[1] Gu Lingyuan, Wang jie. Teacher Growth in Educational Activities. Global Education. 2003(1):44-49.

[2] Yang yudong. How do teachers do lesson study. Research in educational development. 2008(8):79-83.

[3] Pattison P, Russell D. Instructional skills workshop (ISW) handbook[M]. Vancouver: UBC Centre for Teaching and Academic Growth,2006:42-63. 